\title{
Molecular Detection of Virulence Genes among Pseudomonas aeruginosa Strains Isolated from Clinical Specimens by Multiplex PCR
}

\author{
Afsoon Shariat ${ }^{1, *}$, Sajad Alizadeh $^{2}$, Mehdi Jahangiri Hoseinabadi², Mohammad \\ Movagharnejad $^{2}$ \\ ${ }^{I}$ Assistant Professor, Department of Microbiology, School of Basic Sciences, Kazerun Branch, Islamic Azad University, \\ Kazerun, Iran \\ ${ }^{2}$ PhD Student, Department of Microbiology School of Basic Sciences, Kazerun Branch, Islamic Azad University, Kazerun, \\ Iran \\ * Corresponding Author: Afsoon Shariat, Department of Microbiology, School of Basic Sciences, Kazerun Branch, Islamic \\ Azad University, Kazerun, Iran. Email: afsoonsh1980@yahoo.com
}

\section{Abstract}

Received: 30.12 .2017

Accepted: 16.04.2018

How to Cite this Article:

Shariat A, Alizadeh S, Jahangiri Hoseinabadi M, Movagharnejad M. Molecular Detection of

Virulence Genes among Pseudomonas aeruginosa Strains Isolated from Clinical Specimens by Multiplex PCR. Avicenna $J$ Clin Med. 2018; 25(1): 28-34. DOI: $10.21859 / \mathrm{ajcm} .25 .1 .28$.
Background and Objective: Pseudomonas aeroginosa is the most common pathogen associated with nosocomial infections and possesses virulence factors which contribute to the bacterial invasion and toxicity such as alginate, exoenzyme $\mathrm{S}$, exotoxin $\mathrm{A}$ and elastase. The aim of this study was to determine the prevalence of algD, exoS, tox $A$ and las $B$ genes in Pseudomonas aeruginosa samples isolated from patients by Multiplex PCR. Materials and Methods: In this cross sectional study, sixty clinical samples were collected from Dey and Motahhari Hospitals, Tehran, Iran. Following identification of isolates by biochemical methods, Antibiogram test was performed using disc diffusion method with different antibiotics. Multiplex PCR method was performed to identify the desired genes.

Results: 37 out of $60(61.66 \%)$ male and 23 out of $60(38.34 \%)$ female specimens were positive for pseudomonas aeruginosa. The highest level of antibiotic resistance of the Pseudomonas aeroginosa isolates was observed against ceftriaxone (93.33\%). The prevalence rate of virulence genes among all isolates was as follows; $\operatorname{las} B(61.7 \%)$, toxA $(60 \%), \operatorname{alg} D(43.3 \%)$ and $\operatorname{exoS}(5 \%)$.

Conclusion: Elastase, exotoxin A and alginate are considered important virulence factors of pseudomonas aeruginosa and they play a major role in causing diseases and tissue and skin lesions.

Keywords: Genes, Multiplex PCR, Pseudomonas aeruginosa 


\title{
تشخيص ملكولى ذنهاى بيمارىزا در سويههاى سودوموناس آئروزينوزاى جداشده از Multiplex PCR نمونهاى بالينى با روش
}

\author{
افسون شريعت ا."، سجاد عليز اده '، مهدى جهانغيرى حسين آبادى '، محمد موقرنزاد'r \\ ' استاديار، كروه ميكروبشناسى، دانشكده علوم پايه، واحد كازرون، دانشكاه آزاد اسلامى، كازرون، ايران

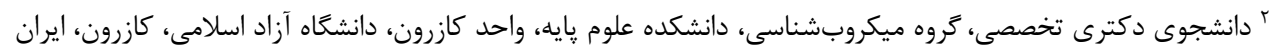 \\ * نويسنده مسئول: افسون شريعت، كروه ميكروبشناسى، دانشكده علوم پايه، واحد كازرون، دانشخاه آزاد اسلامى، كازرون، ايران. \\ ايميل: afsoonsh1980@yahoo.com
}

\begin{tabular}{|c|c|}
\hline 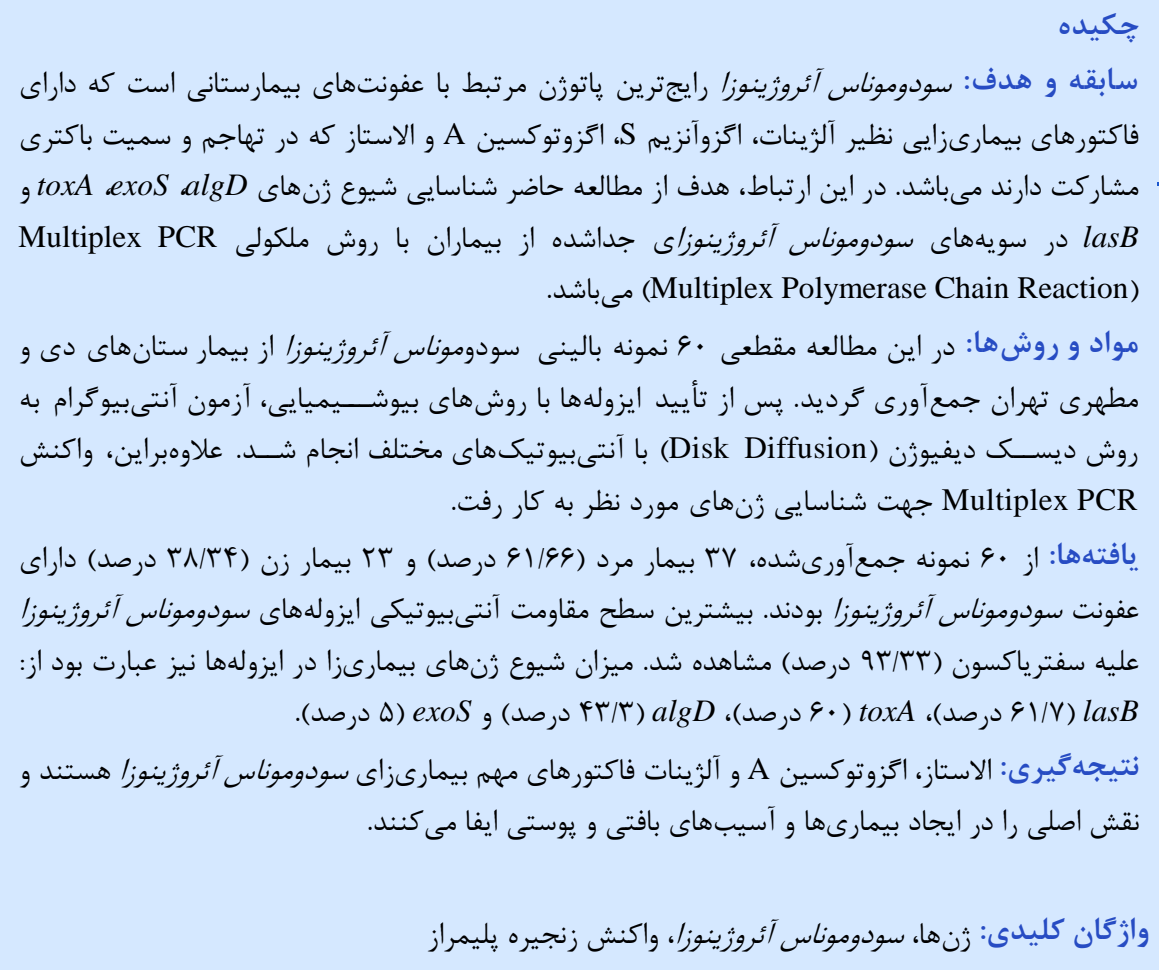 & 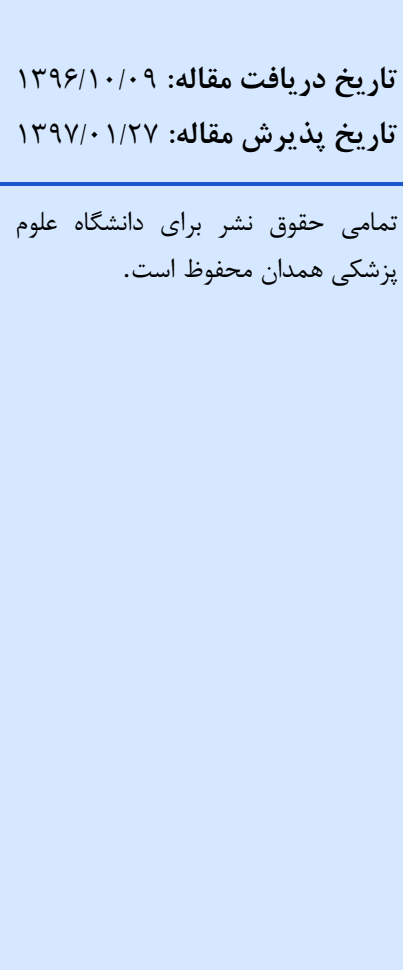 \\
\hline
\end{tabular}

سودوموناس آئروزينوزا بيشتر توسط عوامل بيمارىزاى ييلى

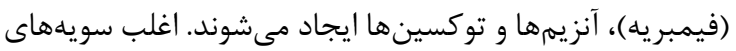

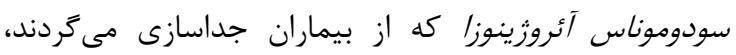

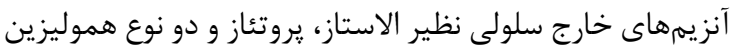
شامل: فسفوليياز C حساس به حرارت و يك حليكوليييد مقاوم

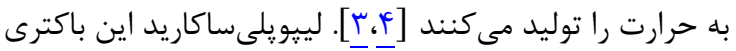
نيز نقش مستقيمى در ايجاد تب، شوك، لكوسيتوز، لكوينى و

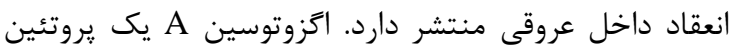

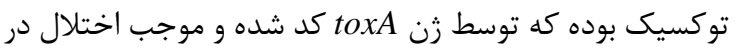

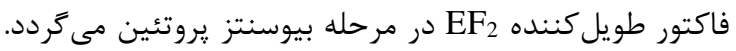

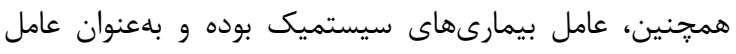

سودوموناس آئروزينوزا ميكرواركانيسمى با قابليت تحرك،

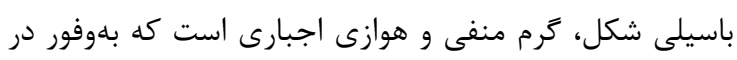

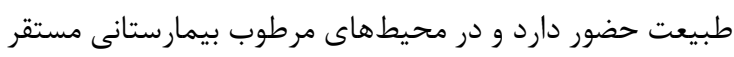

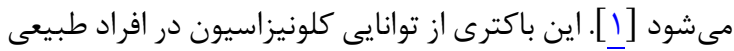

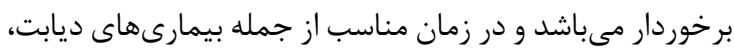

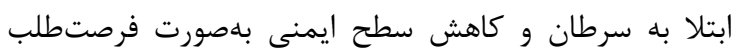

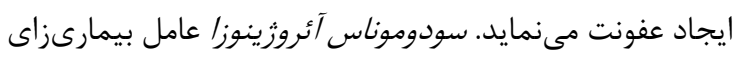

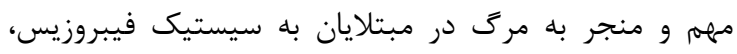

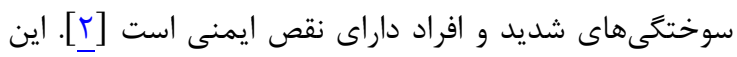

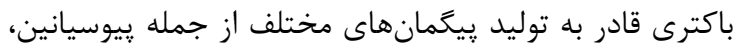

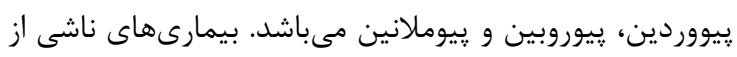


آلمان) كشت داده شدند و به مدت YF ساعت در دماى YV درجه

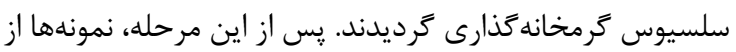
نظر شكل كلنى و تغييرات ايجادشده در محيطهاى مورد استفاده

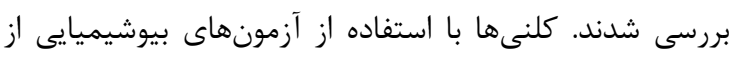

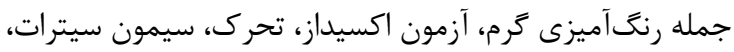
Oxidative ) OF Triple Sugar Iron) TSI (Fermentative سلسيوس و توليد بِيخمان در محيط ستريميد آتار مورد تأييد

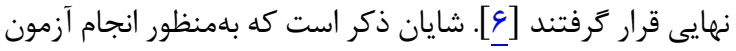

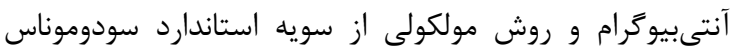
آئروزينوزا

\section{تعيين الكوى مقاومت آنتسبيوتيكى در سويههاى سودوموناس آئروزينوزا}

براى انجام آزمون آنتى بيوكرام با ديسكورلهاى تجارى مشخص

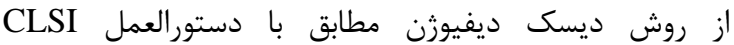
استفاده (Clinical and Laboratory Standards Institute) شد [V]]. ديسكهاى آنتىبيوتيك مورد استفاده شامل:

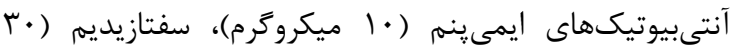

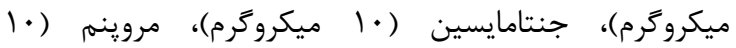

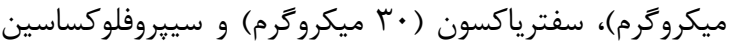

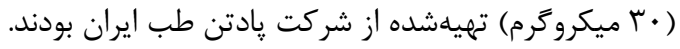

استخراج DNA و واكنش Multiplex PCR براى تكثير ثنهاى tax

جهت استخراج DNA زنومى نمونهها از كيت تجارى مركز

ذخاير زنتيكى و زيستى ايران مخصوص باكترىهاى كرم منفى

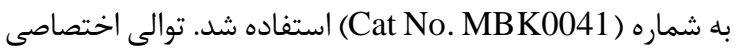
يرايمرهاى زنهاى مورد مطالعه (lasB toxA exoS،

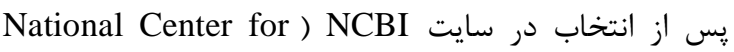
(Biotechnology Information

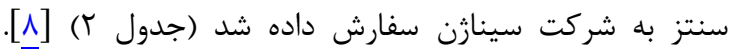

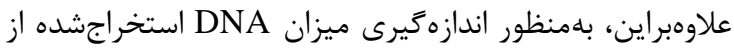

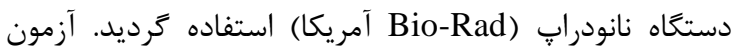

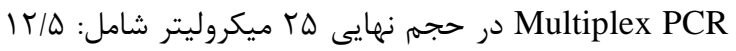
ميكروليتر PCR master mix 2X (سيناكلون، ايران)، ها •

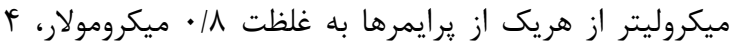

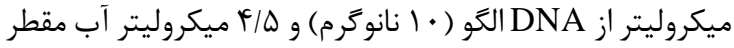
استريل انجام شد. برنامه واكنش PCR در دستخاه ترموسايكلر

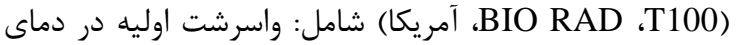
F ثانويه در دماى ₹

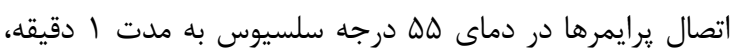

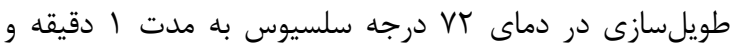

كمك كننده در كلونيزاسيون باكترى محسوب مىشود [1]]. زن

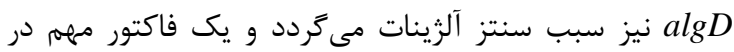

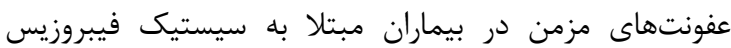

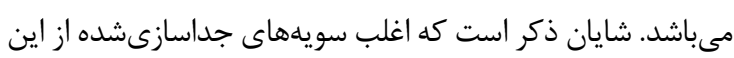
بيماران واجد كلونى هاى موكوئيدى مى باشند كه با حضور اين زن

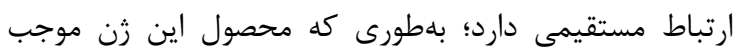

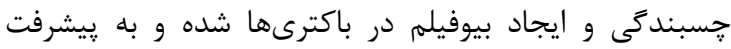

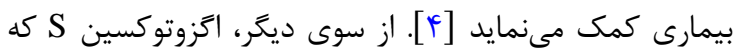

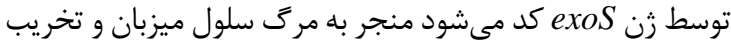

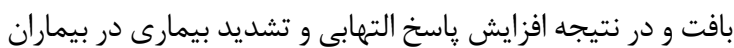

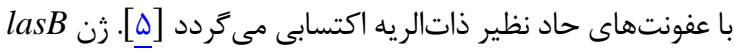

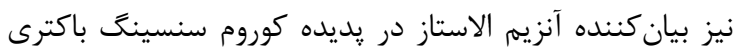

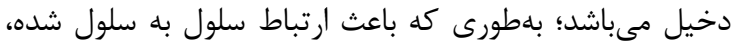

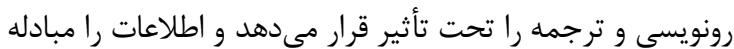

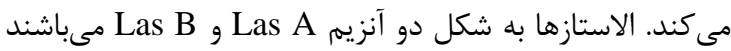
كه بلهورت همافزايى وارد عمل شده و منجر به تجزيه الاستين

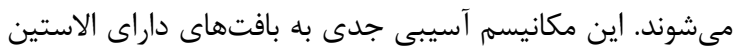

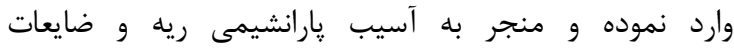
خونريزى از اين مطالعه شناسايى ملكولى زنهاى exoS، algD، lasB

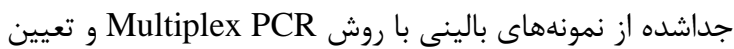

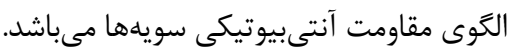

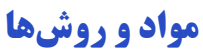

جمعآورى نمونه ها و شناسا يي سودوموناس آئروثينوزا در اين مطالعه مقطعى كه در بازه زمانى مهر ماه تا دى ماهو ماه

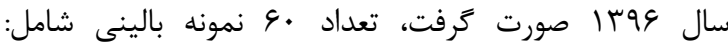

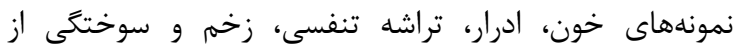

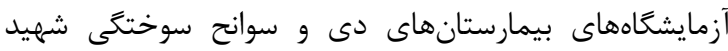

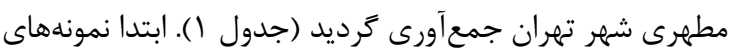

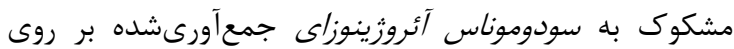

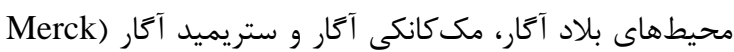

جدول ا: نمونههاى بالينى واجد عفونت سودوموناس آئروزينوزا

\begin{tabular}{|c|c|c|}
\hline \multicolumn{2}{|c|}{ تعداد نمونه } & \multirow{2}{*}{ نوع نمونه بالينى } \\
\hline زن & مرد & \\
\hline v & ז & عفونت زخم \\
\hline 11 & IV & سوختكى \\
\hline f & r & عفونت ادرارى \\
\hline 1 & r & عفونت تنفسى \\
\hline- & r & عفونت خون \\
\hline r & rv & تعداد كل \\
\hline
\end{tabular}


جدول ץ: توالى برايمرهاى مورد استفاده جهت تكثير زنهاى toxA، lasB algD و

\begin{tabular}{|c|c|c|}
\hline 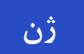 & 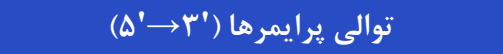 & اندازه محصول (bp) \\
\hline $\operatorname{alg} D$ & $\begin{array}{l}\text { F: ATGCGAATCAGCATCTTTGGT } \\
\text { R: CTACCAGCAGATGCCCTCGGC }\end{array}$ & |rו. \\
\hline $\operatorname{las} B$ & $\begin{array}{l}\text { F: GGAATGAACGAAGCGTTCTC } \\
\text { R: GGTCCAGTAGTAGCGGTTGG }\end{array}$ & r.. \\
\hline toxA & $\begin{array}{l}\text { F: GGTAACCAGCTCAGCCACAT } \\
\text { R: TGATGTCCAGGTCATGCTTC }\end{array}$ & rar \\
\hline $\operatorname{exoS}$ & $\begin{array}{l}\text { F: CTTGAAGGGACTCGACAAGG } \\
\text { R: TTCAGGTCCGCGTAGTGAAT }\end{array}$ & $\Delta \cdot F$ \\
\hline
\end{tabular}

به آنتىبيوتيك سفترياكسون وها (سr/سף درصد) بوده و بيشترين

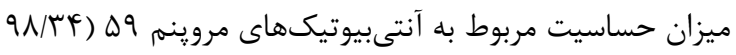

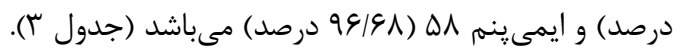

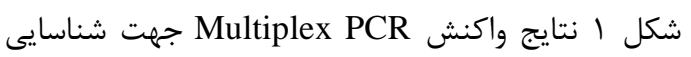

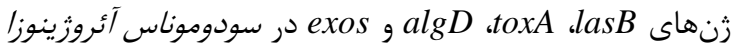

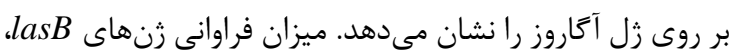
exoS algD toxA

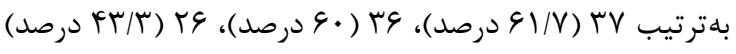

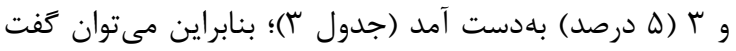
كه بيشترين ميزان فراوانى مربوط به زن إنهاى

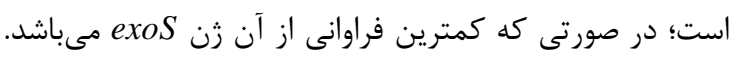

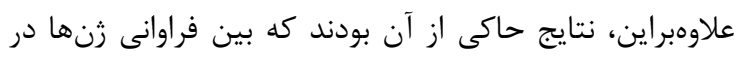

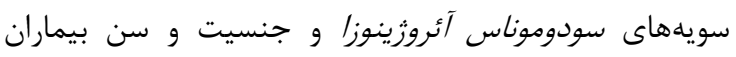
اختلاف معنادارى وجود ندارد (ه • (P> (P).
مرحله بسط نهايى در دماى Y ل درجه سلسيوس به مدت ه دقيقه

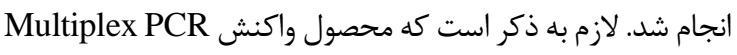

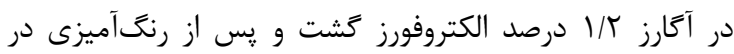
دستخاه زل داك (BIO RAD، آمريكا) مشاهده گرديد.

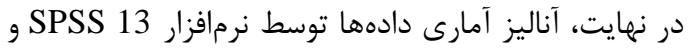

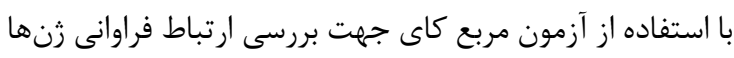
با جنسيت و سن بيماران صورت گرفت. سطح معنادارى نيز كمتر

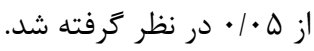

از ميان • • نمونه سودوموناس آئروزينوزاى جمع آورىشده،

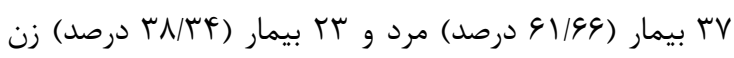

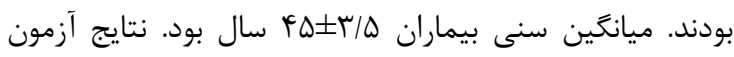

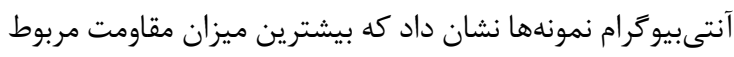

\begin{tabular}{|c|c|c|c|}
\hline (درصد) تعداد & (درصد) تعداد & (درصد) تعداد & نوع آنتىبيوتيك \\
\hline$\Delta \Lambda(99 \mid 9 \wedge)$ & $1(1 / 99)$ & $1(1 / 99)$ & ايمى ينم \\
\hline$\Delta \Delta(91 / 94)$ & - & $\Delta(\Lambda / K F)$ & سفتازيديم \\
\hline - & $f(9 / 9 \mathrm{~V})$ & 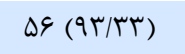 & سفترياكسون \\
\hline $49(1 / / 99)$ & - & $\|(\mid N / M F)$ & سيبروفلوكساسين \\
\hline$\Delta q(q \wedge / \Gamma Y)$ & - & $1(1 / 99)$ & مروينم \\
\hline$\Delta \varphi(q \mu / r)$ & - & $F(\xi \mid \xi V)$ & جنتامايسين \\
\hline
\end{tabular}

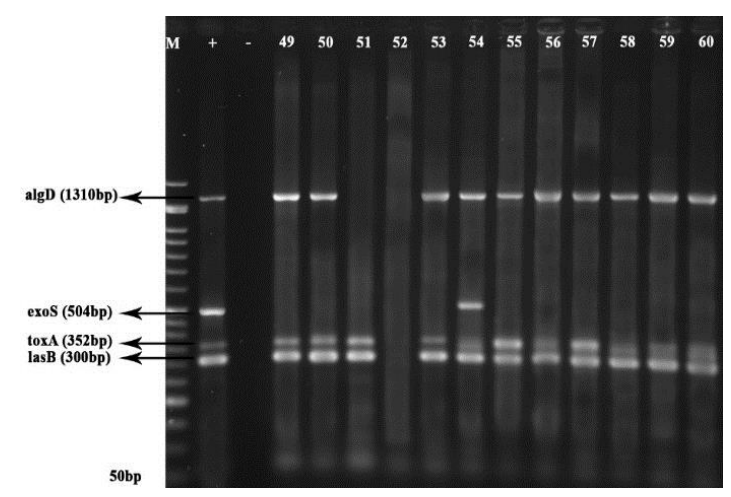

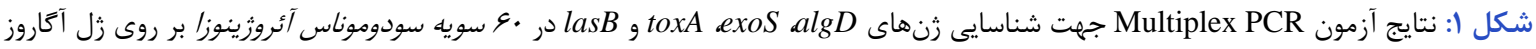

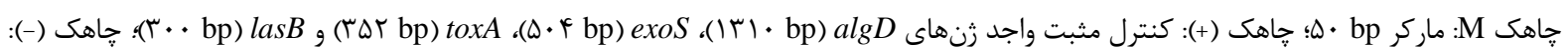

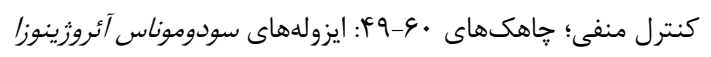




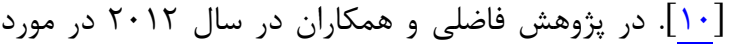

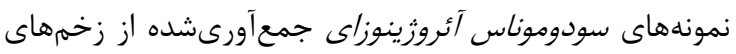

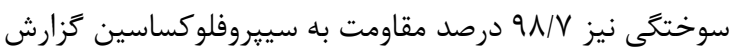

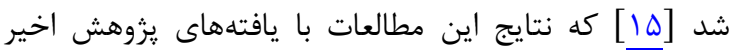

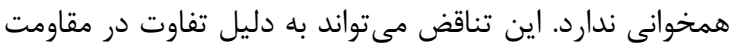

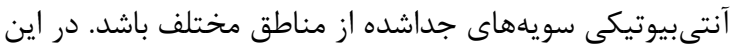

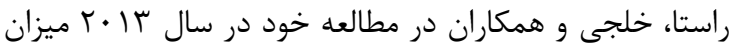

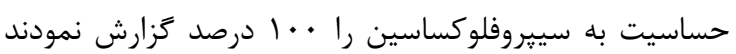

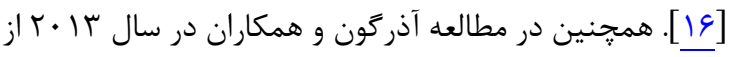

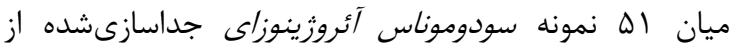

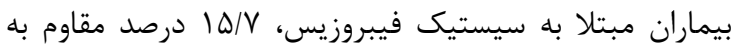

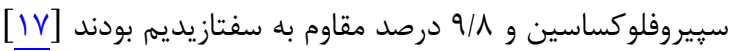

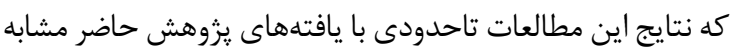

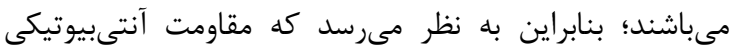

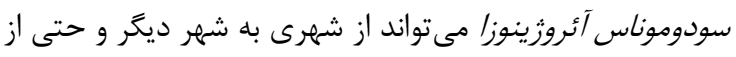

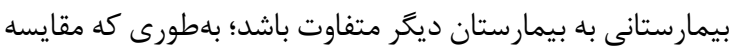

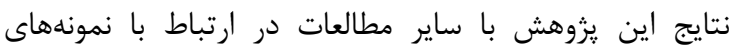

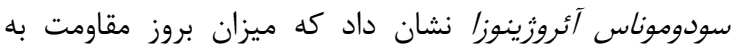

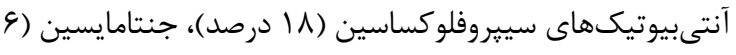

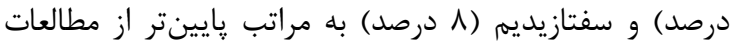

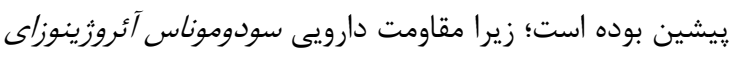

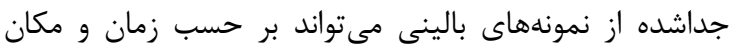

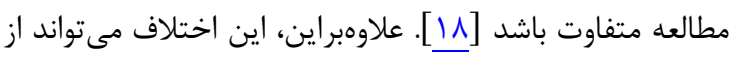

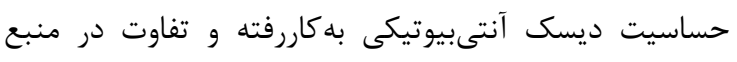

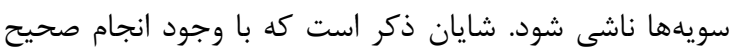

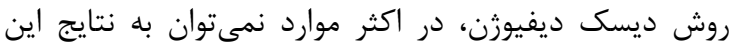

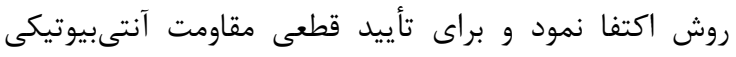

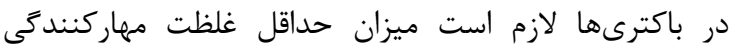
نيز تعيين (MIC: Minim Iminhibitory Concentration)

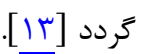

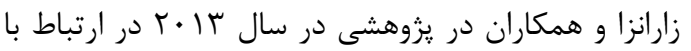

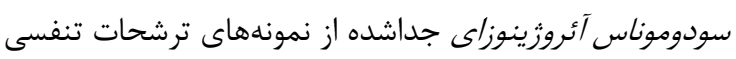

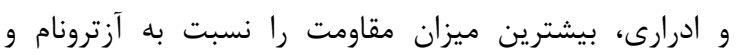

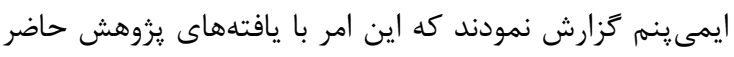

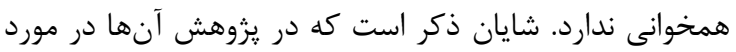

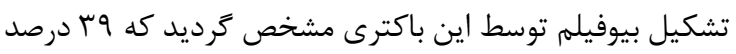
از سويههاى سودوموناس آئروزينوزا واجد زن بن

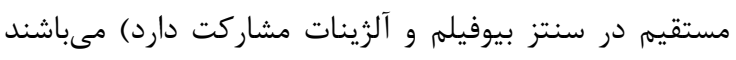

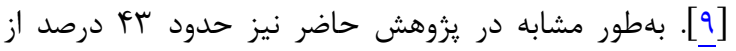

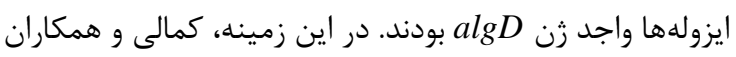

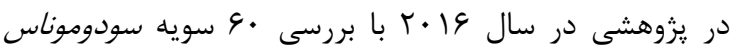

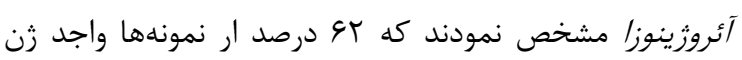

اكزوتوكسين A مىباشند [19]
باكترى سودوموناس آئروزينوزا با داشتن فاكتورهاى حدت

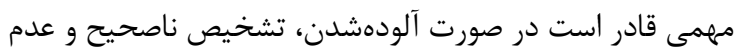

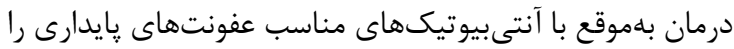

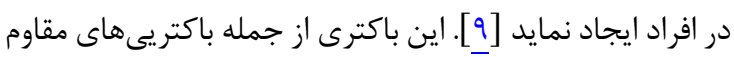

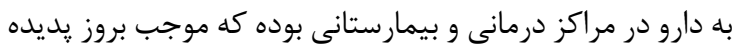

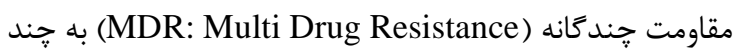

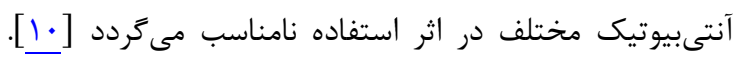

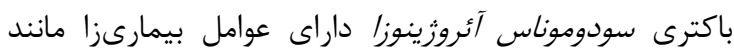

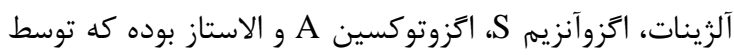

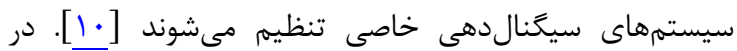
مطالعه حاضر ميزان شيوع زنهاى بيمارىزاى Multiplex PCR با استفاده از روش ملكون بـ tasB toxA

$$
\text { مورد ارزيابى قرار كرفت. }
$$

امينى بزنجانى و همكاران طى مطالعهاى در سال

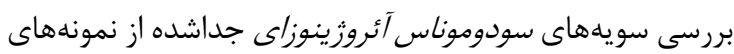

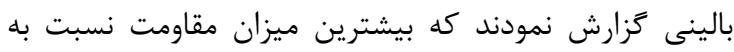

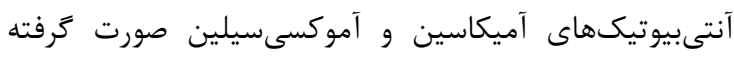

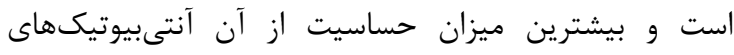

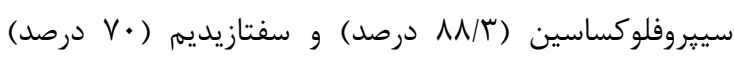

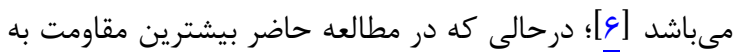

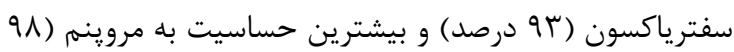

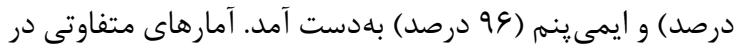

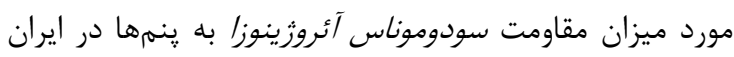

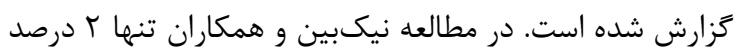

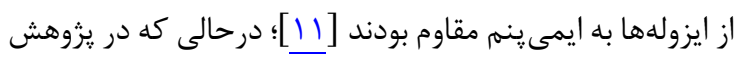

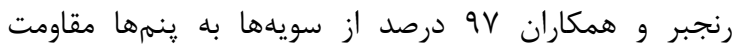

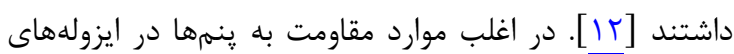

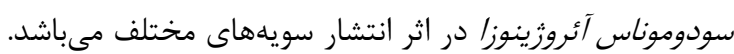

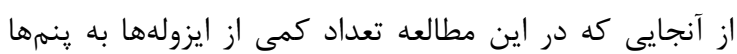

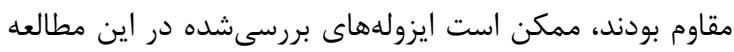

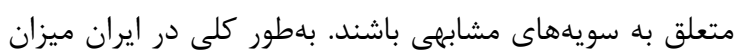

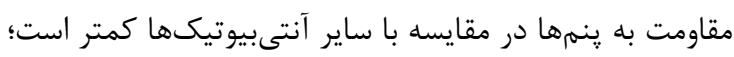

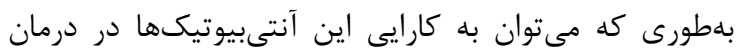

عفونتهاى سودوموناسى اميدوار بود [ـإن]

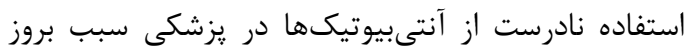

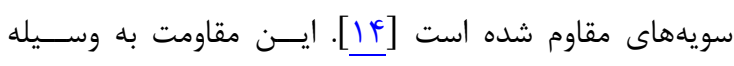

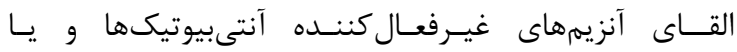

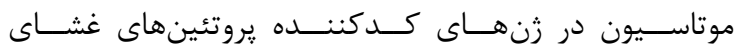
خارجى باعث تغيير در كيرنده و يا محل اثر آنتىبيوتيكها

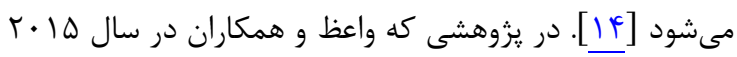

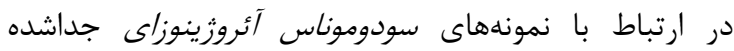

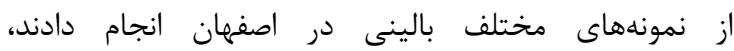

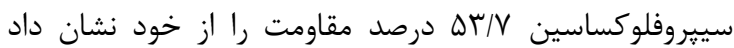


در روش مولكولى را حساسيت بيشتر اين روش در شناسايى

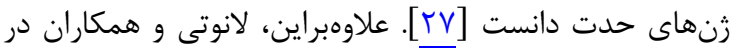

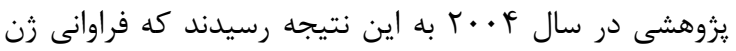
lasB [^]؛؛ اما در اين مطالعه فراوانى زنهاى lasB، exoS

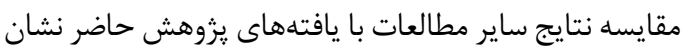

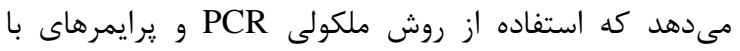

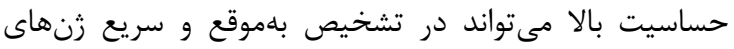

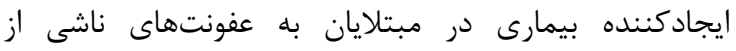

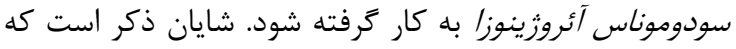

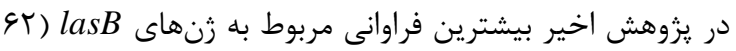

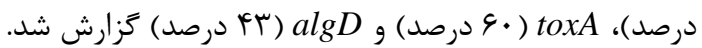

\section{نتيجه تَيرى}

در بيماران مبتلا به عفونتهاى سودوموناس آئروزينوزا، زن هاى حدت بيان كننده آنزيم الاستاز، اكزوتوكسين A و آلزينات

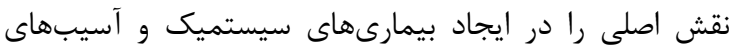

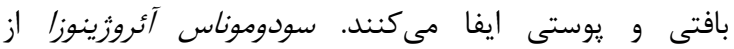

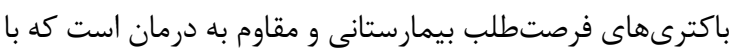

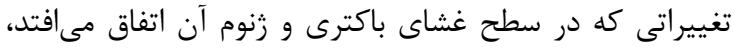

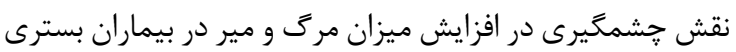

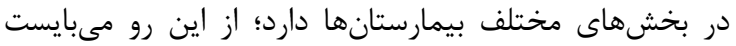

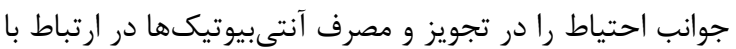
بيماران مبتلا به عفونتهاى سودوموناس آئروزينوزا رعايت نمود.

\section{تشكر و قررقاذى}

اين مقاله بركرفته از طرح تحقيقاتى دانشجويى مصوب

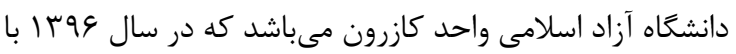

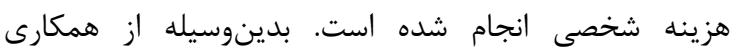

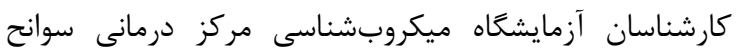
سوختكى تهران قدردانى مىشود.

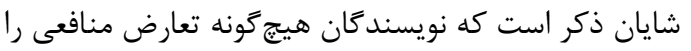

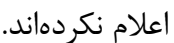

\section{REFERENCES}

1. Khan AA, Cerniglia CE. Detection of Pseudomonas aeruginosa from clinical and environmental samples by amplification of the exotoxin A gene using PCR. Appl Environ Microbiol. 1994;60(10):3739-45. PMID: 7986047

2. Ramsey DM, Wozniak DJ. Understanding the control of Pseudomonas aeruginosa alginate synthesis and the prospects for management of chronic infections in cystic fibrosis. Mol Microbiol. 2005;56(2):309-22. PMID: 15813726 DOI: $10.1111 /$ j.1365-2958.2005.04552.x

3. Stonehouse MJ, Cota-Gomez A, Parker SK, Martin WE, Hankin JA, Murphy RC, et al. A novel class of microbial phosphocholine-specific phospholipases C. Mol Microbiol. 2002;46(3):661-76. PMID: 12410824

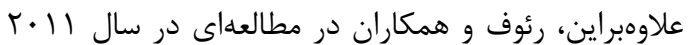

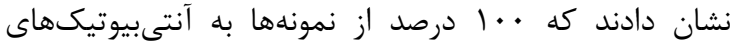

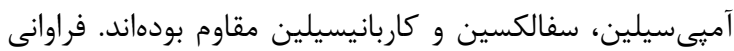

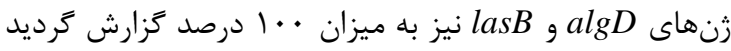

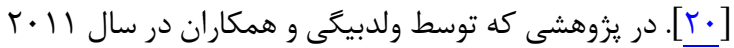

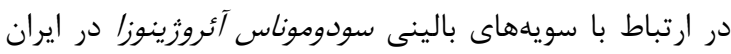

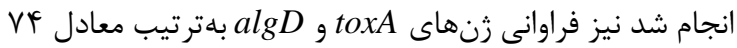

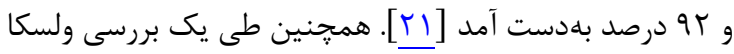

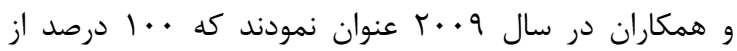

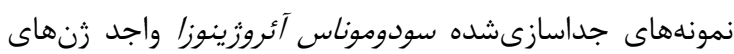
algD و مى alasB

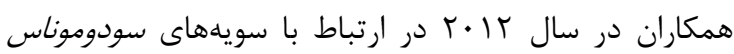
آئروزينوزای جداشده از نمونههاى عفونى مختلف در ايران اندان انجام

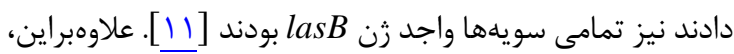
طى يزوهش صورت

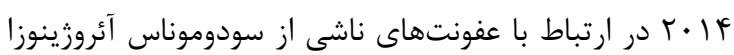

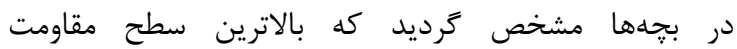

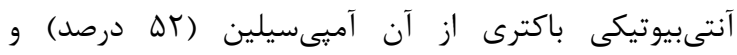

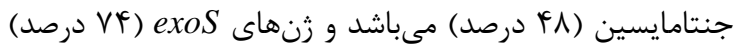

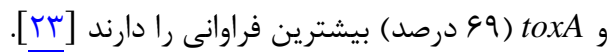

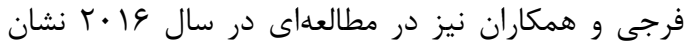

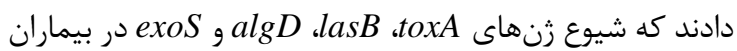
دجار سوختكى بهترتيب لr

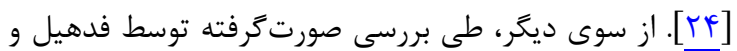

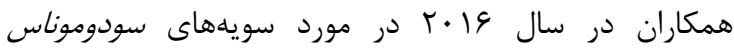

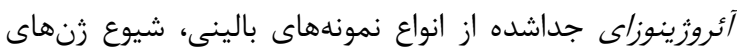
lasB toxA

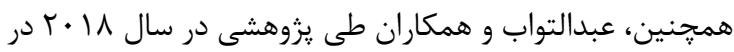

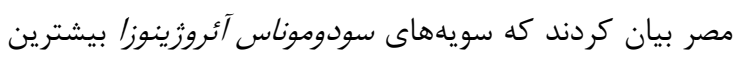

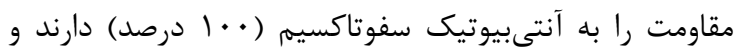

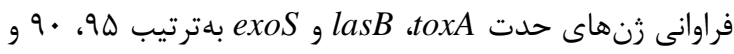

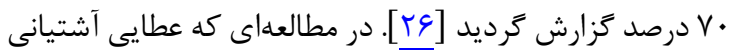

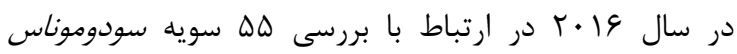

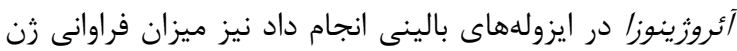

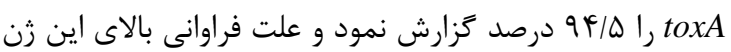

4. Najafimosleh M, Rashnotaie S, Ghaznavirad E, Abtahi H, Taleie G. Designing of the specific DNA primers for detection of the exoA, oprL and algD pathogenicity genes for rapid diagnosis of Pseudomonas aeruginosa. Tehran Univ Med J. 2013;71(8):493-501. [Persian]

5. Zhu H, Conibear TC, Bandara R, Aliwarga Y, Stapleton F, Willcox MD. Type III secretion system-associatedtoxins, proteases, serotypes, and antibiotic resistance of Pseudomonas aeruginosa isolates associated with keratitis. Curr Eye Res. 2006;31(4):297-306. PMID: 16603462 DOI: 10.1080/02713680500536746

6. Amini Bezanjanii F, Mahmoudi R, Amini K. Study and identification Quorum Sensing (QS) genes of Pseudomonas 
aeruginosa strains isolated from samples of human clinical by Multiplex PCR and determine antibiotic resistance. Yafteh. 2016;18(2):38-44. [Persian]

7. Wikler MA. Performance standards for antimicrobial disk susceptibility tests: approved standard: Clin Lab Stand Inst. 2006;26(3):1-183.

8. Lanotte P, Watt S, Mereghetti L, Dartiguelongue N, Rastegar-Lari A, Goudeau A, et al. Genetic features of Pseudomonas aeruginosa isolates from cystic fibrosis patients compared with those of isolates from otherorigins. $J$ Med Microbiol. 2004;53(1):73-81. PMID: 14663109 DOI: 10.1099/jmm.0.05324-0

9. Zaranza AV, Morais FC, do Carmo MS, de Mendonça Marques A, Andrade-Monteiro C, Ferro TF, et al. Antimicrobial susceptibility, biofilm production and adhesion to HEp-2 cells of Pseudomonas aeruginosa strains isolated from clinical samples. J Biomat Nanobiotechnol. 2013;4(1):98.

10. Vaez H, Faghri J, Nasr Esfahani B, Moghim S, Fazeli H, Sedighi M, et al. Antibiotic resistance patterns and genetic diversity in clinical isolatesof pseudomonas aeruginosa isolated from patients of a referral hospital, Isfahan, Iran. Jundishapur $J$ Microbiol. 2015;8(8):e20130. PMID: 26468363 DOI: $10.5812 /$ jim.20130v2

11. Nikbin VS, Aslani MM, Sharafi Z, Hashemipour M, Shahcheraghi F, Ebrahimipour G. Molecular identification and detection of virulence genes among Pseudomonas aeruginosa isolated from different infectious origins. Iran J Microbiol. 2012;4(3):118-23. PMID: 23066485

12. Ranjbar R, Owlia P, Saderi H, Mansouri S, Jonaidi-Jafari N, Izadi M, et al. Characterization of Pseudomonas aeruginosa strains isolated from burned patients hospitalized in a major burn center in Tehran, Iran. Acta Med Iran. 2011;49(10):6759. PMID: 22071644

13. Ahmadi A, Soltanpour MM, Imani Fooladi AA. Prevalency of imipenem-resistant bacterial strains isolated from hospital and accuracy of Iranian imipenem disc product. $J$ Gorgan Univ Med Sci. 2015;17(1):61-6. [Persian]

14. López-Causapé C, de Dios-Caballero J, Cobo M, Escribano A, AsensioO, Oliver A, et al. Antibiotic resistance and population structure of cystic fibrosis Pseudomonas aeruginosa isolates from a Spanish multi-centre study. Int J Antimicrob Agents. 2017;50(3):334-41. PMID: 28735882 DOI: 10.1016/j.ijantimicag.2017.03.034

15. Fazeli H, Akbari R, Moghim S, Asadian A, Faghihinia J, Saneeyan H, et al. Detection of morphotyping characteristics identification antibiotic resistance of Pseudomonas aeruginosa isolated from patients with cystic fibrosis. J Isfahan Med Sch. 2012;29(171):1-12.

16. Khalaji Y, Doosti A, Ghorbani-Dalini S. Molecular evaluation of antibiotic resistance prevalence in
Pseudomonas aeroginosa isolated from cockroaches in Southwest Iran. Int J Med Med Sci. 2013;5(9):420-4.

17. Azargoon R, Doustdar F, Khanbabaei G, Mehrnejad F, Goudarzi H. Type III secretion system characterization of Pseudomonas aeruginosa associated with cystic fibrosis. Res Med. 2013;37(3):189-93. [Persian]

18. Golshani Z, Ahadi AM, Sharifzadeh A. Antimicrobial susceptibility pattern of Pseudomonas aeruginosa isolated from patients referring to hospitals. Arch Hyg Sci. 2012;1(2):48-53. [Persian]

19. Kamali A, Amini K. Concurrent isolation of virulence genes ETA, oprL, gyrB in Pseudomonas aeruginosa clinical samples from hospitals in Kerman by Multiplex-PCR. $J$ Shahrekord Univ Med Sci. 2016;18(3):48-56. [Persian]

20. Ra'oof WaM. Distribution of algD, lasB, pilB and nan 1 genes among MDR clinical isolates of Pseudomonas aeruginosa in respect to site of infection. Tikrit Med J. 2011;17(2):148-60.

21. Valadbeigi H, Sadeghifard N, Rafiei TR, Maleki A. A study on the frequency of toxin A, Alginate genes, and of clinical Pseudomonas aeroginosastrains. J Ilam Univ Med Sci. 2011;20(1):58-64. [Persian]

22. Wolska K, Szweda P. Genetic features of clinical Pseudomonas aeruginosa strains. Pol J Microbiol. 2009;58(3):255-60. PMID: 19899619

23. Dadmanesh M, Pilehvarzadeh M, Eramabadi M, Eramabadi P, Bagheri Moghadam M, Mashayekhi F. Community acquired Pseudomonas aeroginosaurinary tract infections in children hospitalized in a Baqiatallah hospital, Tehran, Iran: Virulence profile and antibiotic resistance properties. Biosci Biotech Res Asia. 2014;11(2):417-26.

24. Faraji F, Mahzounieh M, Ebrahimi A, Fallah F, Teymournejad O, Lajevardi B. Molecular detection of virulence genes in Pseudomonas aeruginosa isolated from children with Cystic Fibrosis and burn wounds in Iran. Microb Pathog. 2016;99:1-4. PMID: 27457974 DOI: 10.1016/j.micpath.2016.07.013

25. Fadhil L, Al-Marzoqi AH, Al Taee ZM, Shalan AA. Molecular and phenotypic study of virulence genes in a pathogenic strain of Pseudomonas aeruginosaisolated from various clinical origins by PCR: profiles of genes and toxins. Res J Pharm Biol Chem Sci. 2016;7(1):590-8.

26. Abd El-Tawab AA, El-Hofy F, Khater DF, Al-Adl MM. Virulence, resistance genes detection and sequencing of gyrAGene of Pseudomonas aeruginosa isolated from chickens and human in Egypt. Nat Sci. 2018;16(2):32-9.

27. Ataee-Ashtiani M Z-ST. Molecular detection of the genes gyrB, oprL, ETA, 16SrDNA in Pseudomonas aeruginosastrains isolated from clinical samples of Karaj city health centers, Iran. J Isfahan Med Sch . 2016;33(360):20438. [Persian] 